\title{
Formação de professores e saberes docentes: trajetória e preocupações de uma pesquisadora da docência - uma entrevista com Ruth Mercado
}

Denise Trento Rebello de Souzal

Marli Lúcia Tonatto Zibettil

\section{Resumo}

A entrevista concedida pela pesquisadora mexicana Ruth Mercado Maldonado em outubro de 2013 traz importantes contribuições para o campo educacional ao tratar de temas contemporâneos a partir da experiência profissional de uma investigadora de renome internacional. Docente e pesquisadora do Departamiento de Investigaciones Educativas del Centro de Investigación y de Estudios Avanzados del Instituto Politécnico Nacional (DIE-CINVESTAV), a Dra. Ruth Mercado mantém contato com pesquisadores brasileiros desde a década de 1980, debatendo temas envolvendo a etnografia e a formação de professores. A abordagem etnográfica, calcada na articulação entre trabalho empírico e conceitual, possibilita que a autora, a partir do pensamento de Agnes Heller, Mikhail Bakhtin e Lev Vigotsky, dentre outros, produza uma construção teórica própria acerca dos saberes docentes. Sua trajetória revela as concepções de uma pesquisadora que busca compreender a perspectiva do outro, distanciando-se dos olhares avaliativos e prescritivos comuns ao campo pedagógico. $\mathrm{Na}$ entrevista, a autora aborda, de modo instigante, questões atuais e relativas ao campo da formação inicial e continuada de professores: o processo de universitarização e suas implicações, o papel dos formadores, as relações entre cultura universitária e cultura escolar. Suas reflexões sobre a história da profissão docente no México e da criação de programas de mestrado profissional em diferentes países oferecem contribuições importantes para a comunidade educacional da América Latina. A leitura da entrevista envolve, assim, um convite à reflexão sobre os desafios que a universidade e seus profissionais enfrentam na construção de propostas de formação docente adequadas às necessidades, demandas e características próprias daqueles que atuam na educação básica.

\section{Palavras-chave}

I- Universidade de São Paulo, São Paulo, SP, Brasil.

Contato: dtrento@usp.br

II- Universidade Federal de Rondônia, Porto Velho, RO, Brasil.

Contato: marlizibetti@yahoo.com.br
Etnografia - Formação docente - Saberes docentes - Universitarização - DIE-CINVESTAV. 


\section{Teacher education and teachers knowledges: trajectory and concerns of a researcher in teaching - an interview with Ruth Mercado}

Denise Trento Rebello de Souza'

Marli Lúcia Tonatto Zibettill

I- Universidade de São Paulo, São Paulo, SP, Brazil. Contact: dtrento@usp.br

II- Universidade Federal de Rondônia, Porto Velho, RO, Brazil.

Contact: marlizibetti@yahoo.com.br

\section{Abstract}

The text derives from an interview with Mexican researcher Ruth Mercado Maldonado conducted in October 2013, and brings significant contributions to the educational field by dealing with contemporary themes in the light of the professional experience of an internationally renowned scholar. A professor and researcher at the Departamento de Investigaciones Educativas del Centro de Investigación y de Estudios Avanzados del Instituto Politécnico Nacional (DIE-CINVESTAV), Dr Ruth Mercado has been in contact with Brazilian researchers since the 1980s, discussing with them themes involving ethnography and teacher education. The ethnographic approach, based on the articulation between empirical and conceptual works, allows her, drawing from the thinking of Agnes Heller, Mikhail Bakhtin, and Lev Vygotsky, among others, to produce her own theoretical construct about teachers knowledges, seen by her as part of a historical process, thereby revealing the conceptions of a researcher that seeks to understand the perspective of the other, and to distance herself from judgmental and prescriptive outlooks so common in the pedagogical field. In this interview Dr Ruth Mercado stimulates us to reflect about current issues in the field of initial and continued teacher education: the universitization process and its implications, the role of instructors, the relations between university culture and school culture. Her reflections about the history of the teaching profession in Mexico and of the creation of professional master programs in different countries offer important contributions to the educational community in Latin America. The reading of this interview amounts therefore to an invitation to the reflection about the challenges that the university and its professionals face in the construction of teacher education proposals that are adequate to the needs, demands and characteristics specific to those that work in basic education.

\section{Keywords}

Ethnography - Teacher education - Teachers knowledges Universitization - DIE/CINVESTAV. 


\section{Apresentação}

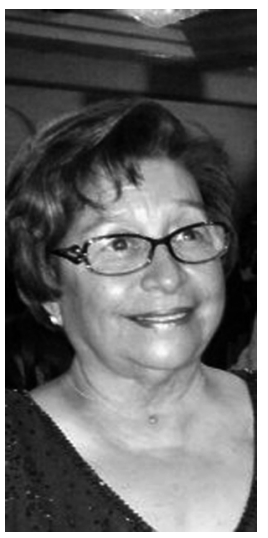

Fonte: Arquivos da autora
A Profa. Ruth Mercado Maldonado é pesquisadora do Departamiento de Investigaciones Educativas do Centro de Investigación y de Estudios Avanzados del Instituto Politécnico Nacional (DIE-CINVESTAV). Nesse departamento, internacionalmente reconhecido pela alta qualidade $e$ pela grande influência na pesquisa educacional da América Latina, ela desenvolve investigações há mais de 25 anos. Também orienta projetos em nível de mestrado e doutorado sobre a docência e o ensino, principalmente em duas linhas de investigação: a) estudos socioculturais sobre a docência cotidiana; b) políticas e processos de formação inicial e continuada de docentes. Profissional envolvida com a educação básica e a formação de professores no México, ela participa tanto de processos de investigação, quanto do desenvolvimento curricular e da produção de materiais pedagógicos. Dentre suas atuações, destaca-se a coordenação, em conjunto com a Profa. Eva Taboada, de projeto para avaliação de desempenho e desenvolvimento docente dos cursos comunitários do CONAFE (Consejo Nacional de Fomento Educativo). Sua expertise lhe rendeu ainda um convite para colaborar como consultora junto à UNESCO.

0 nome de Ruth Mercado está vinculado ao DIE e à sua perspectiva de conceber e realizar a etnografia educacional. ${ }^{1}$ A abordagem etnográfica desenvolvida pelos pesquisadores desse singular departamento do CINVESTAV desperta interesse da comunidade brasileira já nos anos 1980, quando a pesquisa sobre a escola passa por momentos descritos por um segmento da comunidade acadêmica

1- Ver ROCKWELL, 2009 latino-americana como sendo de crise teóricometodológica. ${ }^{2}$ Nos anos subsequentes, iniciase um intercâmbio profícuo entre pesquisadoras do DIE e universidades brasileiras - entre elas, a Universidade de São Paulo. ${ }^{3}$ Durante esse período, a Profa. Ruth Mercado esteve no Brasil a convite da Faculdade de Educação e do Instituto de Psicologia em duas ocasiões, em 1990 e em 2010. Em sua última estada, ela ministrou cursos e desenvolveu trabalhos junto a quatro universidades brasileiras, em diferentes regiões do país. ${ }^{4}$ Em 2013, ela volta ao Brasil na condição de professora visitante da Universidade Federal de Santa Catarina. ${ }^{5}$ É nessa ocasião que nos recebe em Florianópolis para uma entrevista que se estende por quase quatro horas. Ali partilha conosco um pouco de sua trajetória e dos conhecimentos desenvolvidos como pesquisadora do ensino para quem a docência assume lugar central.

Essa marca em seu modo de relacionarse com a pesquisa e o ensino tem forte relação com sua história de formação e atuação profissional. Como ela mesma relata durante a entrevista, existiram momentos-chave. Um deles relaciona-se a um grande projeto de investigação etnográfica realizado na década de 1980, por cinco anos, junto a escolas mexicanas, denominado $O$ contexto social e institucional da escola básica (ROCKWELL, 1980). Tal projeto deu origem aos seus trabalhos de mestrado e doutorado, o que também ocorreu com várias de suas colegas do DIE.

Partícipe de uma das formas por ela consideradas como das mais potentes de fazer etnografia educacional - aquela em que grupos de investigadores partilham todo o processo -,

2- Ver PATTO, 1990; AZANHA, 1990/1991; ROCKWELL, 1987; EZPELETA; ROCKWELL, 1986; SOUZA, 2006; BUENO, 2007; BUENO; SOUZA, 2011.

3- Em 1990, no âmbito de um dos primeiros programas de cooperação internacional (USP-BIRD) mais recentes, docentes da Faculdade de Educação da USP realizaram estágio junto ao DIE-CINVESTAV, dando início ao intercâmbio entre as duas instituições.

4- A Profa. Ruth Mercado esteve no país a convite do LIEPPE (Laboratório Interinstitucional de Estudos e Pesquisas em Psicologia Escolar), do Instituto de Psicologia, e da Faculdade de Educação, com recursos do CNPq.

5- Agradecemos à Profa. Dra. Luciane Maria Schlindwein o empenho em trazer a Profa. Ruth Mercado ao Brasil para mais esse período de intercâmbio profissional. 
Ruth Mercado desponta como pesquisadora no campo da formação de professores, contribuindo para a construção do conceito de saberes docentes (MERCAD0, 2002), a partir de sua participação nesse longo projeto de investigação que, entre outros materiais empíricos, resultou em rico arquivo de observações de sala de aula.

É justamente a abordagem etnográfica, calcada na articulação entre trabalho empírico e conceitual, que possibilita a essa autora uma construção teórica própria acerca dos saberes docentes e que a distingue de outros pesquisadores da área. Apoiando-se no pensamento de Agnes Heller, Mikhail Bakhtin e Lev Vigotsky, entre outros, ela concebe a construção dos saberes docentes como parte de um processo histórico.

Em minha visão, as decisões dos professores e suas estratégias de sobrevivência são parte dos saberes docentes, e a construção destes não implica apenas processos cognitivos ou ações individuais, mas faz parte do processo histórico local da relação cotidiana entre professores e crianças. Nessa história, os professores constroem um conhecimento particular sobre o ensino que articula abordagens provenientes de distintos momentos históricos e espaços sociais. Nesse processo, os professores também elaboram conhecimentos sobre seus alunos, reelaboram suas crenças pedagógicas e suas avaliações acerca dos conteúdos e das formas de ensinar, entre outras coisas. (MERCADO, 2002, p. 19, tradução nossa)

Para a compreensão desse processo de constituição dos saberes, Ruth fundamenta-se no conceito de vida cotidiana, conforme concebido por Agnes Heller (1987): momento do movimento social em que ocorrem as apropriações dos saberes sociais presentes na vida diária.

De Bakhtin (1997), a autora se vale do conceito de dialogia, o qual pressupõe o papel do outro na constituição do sentido dos discursos, pois entende que as palavras enunciadas trazem em si a perspectiva de outras vozes. Nessa direção, a entrevistada defende que é no trabalho cotidiano dos professores que ocorre o processo coletivo de apropriação de saberes, tendo este processo várias dimensões: a história social da docência, a história pessoal de cada professor, o diálogo entre os docentes, destes com seus alunos e com outros sujeitos com os quais convivem. Em tal perspectiva, os saberes docentes são considerados pela autora como "pluriculturais, históricos e socialmente construídos” (MERCAD0, 2002, p. 36).

Em Vigotsky (1977, 1979), Ruth Mercado encontra apoio teórico para fundamentar as relações entre pensamento, linguagem e mundo social.

Assim, o conceito de saberes docentes por ela proposto revela as concepções de uma pesquisadora que busca compreender, por meio dessa abordagem com viés antropológico, a perspectiva do outro, distanciando-se dos olhares avaliativos e prescritivos comuns no campo pedagógico. Seu conhecimento acumulado ao longo dos anos em que coordenou e participou de numerosos projetos de pesquisa sobre a formação docente no México, bem como de outros em que contribuiu para o desenvolvimento de materiais destinados a escolas primárias, secundárias, normais e pós-graduações, qualifica a interlocução dessa pesquisadora.

$\mathrm{Na}$ entrevista, Ruth aborda de modo instigante diversas questões bastante atuais e recorrentes relativas ao campo da formação inicial e continuada de professores: o processo de universitarização e as implicações daí decorrentes, tais como as relações entre formação teórica e formação prática; o papel dos formadores; as relações entre cultura universitária e cultura escolar. Ela também relata elementos importantes da história da profıssão docente no México no caminho de sua profissionalização. Ainda nesse âmbito, a entrevistada nos convida a refletir sobre os desafios que a universidade e nós, acadêmicos, teremos que enfrentar na construção de 
propostas de desenvolvimento profissional docente adequadas às necessidades, demandas e características desse segmento da comunidade educacional - professores da escola básica que, apesar de alvo de nossa atenção há tempos, ainda permanece em parte desconhecido.

Sobre o mestrado profissional, a autora destaca sua importância no campo da formação dos professores da educação básica, bem como a necessidade de construção de um projeto específico com foco na formação dos profissionais do ensino que se diferencie dos mestrados acadêmicos, estes últimos voltados para a formação de pesquisadores.

A escrita nos processos formativos também é tema abordado pela entrevistada, num diálogo em que fica evidente o olhar sensível, próprio dos pesquisadores que dedicaram anos observando e acompanhando atentamente o cotidiano escolar e as transformações da profissão docente. Assim ela vai apresentando suas ideias sobre a produção escrita para professores e sobre as propostas de escrita utilizadas nos processos formativos.

Confiamos que a publicação desta entrevista poderá fomentar debates, sempre bem-vindos, especialmente porque o país passa por modificações substanciais nas políticas de formação de professores, com a implementação de vários programas de formação inicial e continuada que indicam, inclusive, a constituição de novos modelos de formação docente (BUENO; SOUZA, 2012).

\section{Referências}

AZANHA, José Mário Pires. A cultura escolar brasileira: um programa de pesquisas. Revista da USP, São Paulo, n. 8, p. 65-9, 1990/1991.

BAKHTIN, Mikhail. Estética da criação verbal. 2. ed. São Paulo: Martins Fontes, 1997.

BUENO, Belmira Oliveira. Entre a antropologia e a história: uma perspectiva para a etnografia educacional. Perspectiva, Florianópolis, v. 25, n. 2, p. 471-501, jul./dez. 2007.

BUENO, Belmira Oliveira; SOUZA, Denise Trento R. de. Elsie Rockwell: por uma antropologia histórica. In: REGO, Teresa (Org.). Currículo e política educacional: Michael Apple, Thomas Popkewitz, Edgar Morin, Marina Subirats, Elsie Rockwell. Petrópolis: São Paulo: Segmento, 2011. v. 4, p. 145-174.

. Pedagogia contemporânea e formação de professores em serviço: lógicas e dispositivos de um modelo em expansão. In: BITAR,

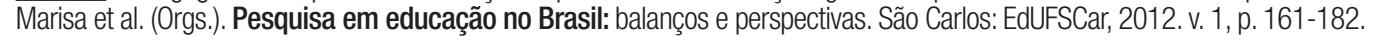

EZPELETA, Justa; ROCKWELL, Elsie. Pesquisa participante. São Paulo: Cortez, 1986.

HELLER, Agnes. Sociología de la vida cotidiana. 2. ed. Barcelona: Ediciones Península, 1987.

MERCADO, Ruth. Los saberes docentes como construcción social: la enseñanza centrada en los niños. México: Fondo de Cultura Económica, 2002.

ROCKWELL, Elsie (Coord.). La práctica docente y su contexto institucional y social. México: DIE-CINVESTAV, 1980. (mimeo)

El proceso etnográfico (1982-1985). Departamento de Investigaciones Educativas, Centro de Investigación y de

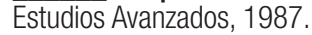

La relevancia de la etnografía. In: Buenos Aires: Paidós, 2009. . La experiencia etnográfica: historia y cultura en los procesos educativos.

SOUZA, Denise Trento R. de. Formação continuada de professores e fracasso escolar: problematizando o argumento da incompetência. Educação e Pesquisa, v. 32, p. 477-492, 2006.

VIGOSTKY, Lev. Pensamiento y lenguaje. Buenos Aires: La Pléyade, 1977.

. El desarrollo de los procesos psicológicos superiores. Barcelona: Grijalbo, 1979.

Denise Trento Rebello de Souza é professora doutora da Faculdade de Educação da Universidade de São Paulo (USP).

Marli Lúcia Tonatto Zibetti é professora doutora do Departamento de Psicologia da Universidade Federal de Rondônia (UNIR). 
Inicialmente, queremos lhe agradecer a disponibilidade em nos receber para essa entrevista. '́ sempre um prazer poder compartilhar ideias com você, Ruth. ${ }^{6}$ Gostaríamos que começasse comentando sobre sua trajetória profissional e seu encontro com as questões e os temas a que tem se dedicado ao longo de sua vida profissional: a pesquisa em sala de aula, os saberes docentes e a perspectiva etnográfica como abordagem para entender os processos e as práticas que constituem a escola.

É uma longa história, muito longa mesmo. Porque já faz algum tempo que eu passei por esses inícios. Acredito que não seja possível contar toda a história dessa trajetória, mas alguns momentos-chave que determinaram, talvez, esse caminho. Olhando para trás, escutando sua pergunta, acho que sempre estive muito próxima dessa inquietação de saber o que se passava na escola. Inicialmente estudei para ser professora de ensino básico. 0 pouco tempo em que, por questões pessoais, trabalhei como professora nesse nível de ensino permitiu-me identificar certas questões que me preocupavam, como as crianças que não conseguiam avançar na escola. Foi por pouco tempo, um ano e meio talvez. Eu era muito jovem e me perguntava sobre o que a escola poderia fazer a esse respeito. Talvez eu não me perguntasse com essas palavras, porque pensar na escola como instituição ou abstração não era ainda uma construção. Fiquei com essas perguntas e me envolvi com o campo da educação, apesar de não ter sido minha iniciativa o ingresso na carreira docente. Essa foi uma decisão tomada pelo meu pai. Sua mãe tinha sido professora entre o final do século XIX e o começo do século XX, quando estudar para ser professora era algo raro e chegava-se a ser professor por meio da prática. Minha avó estudou em uma das primeiras Escolas Normais do México, e eu não sabia disso naquela época.

6- 0 trabalho de transcrição e tradução da entrevista foi realizado por Edilson da Silva Cruz e Camila de Lima Gervaz.
Como primeira filha, meu pai decidiu que eu seria professora. Mas eu não queria isso e fui para a Escola Normal sem o mínimo desejo de ser professora. Queria ser médica. Pensei: faço esse curso e depois estudo o que quero. Quando terminei meus estudos e me tornei professora, interessei-me pelas crianças que ficavam para trás, que a escola não conseguia manter. Decidi estudar educação especial, que nesse tempo apenas começava a ser entendida como um campo próprio da educação. Permaneci por pouco tempo nessa área, pois eu continuava me fazendo uma série de perguntas às quais não conseguia responder.

Também por razões pessoais fui trabalhar em um Estado próximo à Cidade do México, como consultora junto a um departamento de planejamento educacional, que era o que tínhamos de mais moderno. Nesse departamento, as principais funções que desenvolvi foram de assessoria e formação de professores da educação básica. Trabalhávamos diretamente na Secretaria Estadual de Educação, identificando problemas em todos os níveis escolares e elaborando programas e materiais para dar apoio aos professores. Estive muito próxima dos professores de diferentes regiões, desde áreas rurais, indígenas, até as cidades mais importantes do Estado do México. Aprendi muito com essa diversidade e, mais do que isso, essa foi minha escola. Estive, por vários anos, responsável pela educação especial do Estado, inclusive dirigindo uma escola especial por dois anos. Tínhamos professoras de educação especial, atendíamos surdos, crianças com déficit mental, tínhamos também crianças que eram consideradas "com problemas de aprendizado" - entre aspas, porque não sabíamos o que tinham, mas estavam fora da escola e precisavam de um atendimento especial. Essa foi outra grande escola para mim: trabalhar com pais de crianças especiais. Aprendi muito com as mães. A energia que elas têm, a força, a capacidade... Dessa experiência também ficou o aprendizado de um trabalho conjunto, em equipe, com professores especializados em linguagem e ensino de crianças com déficit, 
médicos, psicólogos e enfermeiros. Foi necessário criar estratégias para atender as necessidades dessas crianças.

Consegui também trabalhar com professoras de educação básica - e isso nos anos 1970, ou seja, quando não existiam ainda esses planos de inclusão. E consegui também atuar com professoras de ensino fundamental, não por meio de uma política imposta a elas, mas com visitas às escolas, perguntando quais poderiam aproximar o aluno surdo de um grupo regular. E houve professoras que aceitavam, faziam seu programa e combinavam um tempo conosco depois de sua aula regular.

De onde vieram essas ideias de um tempo na escola regular e um tempo na escola especial?

Já havia algumas ideias no campo da educação especial, mas não havia programas, nem políticas educativas definidas como tais. Eu sabia porque havia estudado, e as professoras de educação especial sabiam que isso podia ampliar as possibilidades educacionais das crianças. Mas o sistema de educação pública não se interessava por isso e quando eu perguntava o que poderiam fazer para levar adiante essas ideias, via-me sozinha. Em síntese, essas experiências me levaram a questionar sobre o que é possível fazer em meio ao abandono das autoridades educativas. Decidi que deveria estudar mais. Os casos que chegavam até nós como problemas de aprendizagem não eram de fato problemas de aprendizagem. Eram problemas decorrentes da pobreza e do abandono social em que as famílias se encontravam. Então, minhas perguntas começaram a se tornar mais elaboradas e mais amplas.

\section{E onde você procurou responder a essas perguntas?}

Nessa época, conheci o Departamiento de Investigaciones Educativas (DIE). Cada vez tenho mais certeza de que tomamos algumas decisões em razão de circunstâncias de vida, mas nem tudo é planejado em nossa trajetória profissional. Há alguns momentos-chave que se apresentam em sua vida e que conduzem a um caminho que talvez você não estivesse procurando. E foram muitas as coincidências. Depois que deixei a direção da escola especial, continuei no departamento de planejamento e comecei a trabalhar junto às salas de aula, com a ideia de saber mais de onde vem a possibilidade de um professor se abrir a experiências difíceis e desafiadoras, como aceitar um aluno surdo em sua classe. Tal interesse me levou a elaborar um projeto que se propunha, além de assessorar, conhecer mais sobre esses professores. Isso porque eu me perguntava: como vamos assessorar os professores se nunca estivemos com eles? Então comecei a ir às salas de aula, ainda de uma maneira improvisada, pois eu não tinha a menor ideia do que fazer com aquilo.

\section{E aí vocês começaram a ir às escolas observar} as professoras...

Vocês, não. Apenas eu fazia isso, porque meus colegas de departamento estavam fazendo mestrado ou algo assim. Meus colegas não tinham essas preocupações, tinham outras, mais relacionadas à psicologia, como elaborar instrumentos para a ficha biopsicossocial. Também comecei fazendo isso e depois parei. Esse foi outro projeto. Minhas colegas perguntavam: "Para que vamos até as escolas? Por que vamos falar com os professores se nós já sabemos o que os professores falam?" "Não acho que sabemos" eu dizia. Fui sozinha e decidi, naquele momento, que iria estudar. Eu tinha colegas que estavam fazendo mestrado no DIE e, a partir das conversas com eles, pensei que gostaria de estudar em um lugar assim. Isso se tornou possível quando alguns professores do departamento convidaramme para trabalhar lá pela minha experiência em educação, o que coincidiu com minha mudança de residência, por motivos pessoais, para a Cidade do México. Iniciei meu trabalho no DIE como assistente no momento em que elaboravam um manual para cursos comunitários, e foi nesse projeto que entrei. Tratava-se de um projeto 
do CONAFE (Consejo Nacional de Fomento Educativo) de cursos comunitários que também incluía a elaboração de material pedagógico para jovens do ensino básico e crianças de escolas rurais, o que me interessava, pois envolvia as escolas e os professores. Depois disso, decidi fazer o mestrado.

\section{Então você começou o mestrado no próprio DIE?}

Sim. Fiz o mestrado e comecei um trabalho de pesquisa, propriamente dito, com minha colega Elsie Rockwell e depois com Justa Ezpeleta. Naquela época, quase ninguém tinha doutorado no DIE. As professoras tinham mestrado e muitos dos projetos que mais tarde se consolidaram como diferenciais do departamento ainda não haviam começado ou estavam apenas começando.

E quem eram seus parceiros nesses anos iniciais do DIE?

Éramos todos muito jovens. Meus colegas dessa época, os que estavam na turma do mestrado, eram universitários que haviam acabado de se formar. Eles não tinham muita experiência na área, enquanto eu vinha de um trabalho muito inserido na vivência educacional, já que, antes de ir para o DIE, eu tive uma experiência de trabalho junto aos pais, às famílias.

Então o tema com que você se envolve com o tempo - os saberes docentes e a pesquisa na sala de aula - tem como origem sua própria inserção no campo da educação, certo?

Claro! Tem essa origem, mas há um pressuposto de que nós nos interessamos pela sala de aula, pelos professores, pelo cotidiano docente, porque somos professores de formação. Contudo, acho que meu envolvimento tem a ver com a minha inserção na educação básica, não somente como professora, mas como alguém que teve a possibilidade de ter acesso a diferentes níveis e estratos da educação básica.
E quais foram as situações que a levaram ao encontro com a pesquisa, mais especificamente na perspectiva da etnografia?

Não sei bem. Começou com Elsie Rockwell e outras colegas, como Grecia Gálvez e, em seguida, Ruth Paradise, ainda nos anos 1970. Logo que entrei no DIE, fiz com Elsie um estudo exploratório que deu lugar ao projeto denominado La práctica docente y su contexto institucional y social, que posteriormente desenvolvemos sob a coordenação por Elsie (ROCKWELL, 1980). Mais adiante tivemos a participação de Justa e a equipe se ampliou com o ingresso de outras pessoas. No título, não constava a expressão escolas rurais; havia subjacente ao projeto uma discussão sobre isso, se eram escolas rurais ou não, se iríamos utilizar essa categoria oficial e se isso era importante. Vimos que nem sempre se tratava de escolas rurais, mas sim de escolas de transição. Enquanto estávamos no local, observávamos que a escola mais rural estava sempre mudando, transformando-se em outra coisa, porque as comunidades iam se urbanizando e algumas ficavam no meio entre o rural e o urbano. Desse projeto saíram vários mestrados - inclusive $o$ meu -, que depois deram lugar a pesquisas de doutorado. A descrição desse processo está em nosso livro La escuela, lugar del trabajo docente. (ROCKWELL; MERCADO, 1999)

Nesse projeto já havia a discussão sobre os saberes?

Não, esse tema decorre do meu doutorado. Meu mestrado abordou os processos de negociação sobre a gratuidade da escola. 0 primeiro aspecto que nós encontramos ao chegar nas escolas era sua parte física, constantemente mudando, de um mês para o outro. Sempre estavam construindo algo - uma parte do muro, um portão, uma sala de aula nova -, arrumando os banheiros que não funcionavam etc. E essa pesquisa sobre a negociação durou aproximadamente cinco anos. Fiquei com muito 
material de sala de aula, e como minha pesquisa de mestrado já estava avançada noutra direção, eu o conservei. Era um material muito rico, em que desde a época do mestrado eu havia identificado coisas relativas ao ensino que me interessavam. Essas análises não me levaram diretamente ao conceito de saberes docentes, mas sim ao doutorado. Notei indícios de coisas que os professores faziam e que o senso comum dizia que eles não faziam. Quando comecei o doutorado, não falava ainda em saberes docentes, mas, depois que terminamos o projeto etnográfico, Elsie e eu publicamos esse livro que acabo de citar e que ficou muito conhecido. Nele, que foi editado pela primeira vez em 1986, incluímos em coautoria o capítulo $L a$ práctica docente y la formación de maestros, em que anunciávamos o tema dos saberes docentes (ROCKWELL; MERCADO, 1999).

Essa questão da abordagem etnográfica nasce com mais força, então, nesse projeto maior que dá origem ao seu mestrado. Foi no bojo desses projetos que a perspectiva etnográfica ganhou corpo e se sistematizou no âmbito do DIE?

Sim. Fomos uma equipe que conseguiu trabalhar muito coletivamente, e acho que a possibilidade de construir etnograficamente, nesse momento da história do departamento, permitiu tal coletividade. Éramos um grupo de cinco ou seis pessoas, e essa coletividade num trabalho etnográfico potencializa a força da etnografia, porque conseguimos partilhar entre nós todos os materiais, as leituras, as discussões e também as inquietações que o campo nos provocava. Há, por exemplo, toda a parte ética. Eu fiquei morando na casa de pessoas próximas às escolas e compartilhávamos a experiência entre a equipe: podíamos fazer debates e saber como cada um se sentia, assim como hoje fazemos com nossos orientandos. Acho que essa é uma boa forma de fazer etnografia. Acho que é a melhor. Quando encerramos esse projeto, eu me envolvi com o ensino que posteriormente associei à formação de professores, pois, nas descobertas sobre os saberes docentes, encontrei forçosamente essa relação com a formação: à medida que se constroem saberes docentes no ensino, está se formando profissionalmente também.

Hoje em dia, levando em consideração o tempo encurtado para o desenvolvimento da pósgraduação, você tem encontrado dificuldades na orientação de pesquisas etnográficas? É possivel ainda manter essa perspectiva?

É possível, mas cada vez menos. É preciso encontrar estudantes que tenham certas características e condições de vida. Por exemplo, meus alunos que são solteiros têm mais tempo, mais independência. Outra coisa: há certas características de personalidade e de formação que permitem um contato mais rápido com outras pessoas. $\mathrm{E}$ isso não se sabe de antemão quando se aceita um estudante. Mas eu insisto que não é preciso ser etnográfico em todos os aspectos, e sim ter a possibilidade de um olhar etnográfico. 0 olhar etnográfico é essa possibilidade de não julgar, não avaliar. No fim das contas, essa é a parte mais difícil, pois o modelo que predomina na perspectiva mais pedagógica atua como se mantivesse os olhos vendados e não fosse além de uma preocupação mais normativa. Se você consegue sair isso e elaborar uma pesquisa com uma perspectiva etnográfica, com rigor conceitual e empírico, o trabalho é feito. A cada dia isso se torna mais difícil, eu concordo, e não só para os estudantes, mas para os pesquisadores também.

Gostaríamos que você comentasse sobre um movimento que tem acontecido aqui no Brasil a partir da Lei de Diretrizes e Bases (LDB) de 1996, que prescreveu a formação em nível superior a todos os professores do país, estipulando um prazo de dez anos para isso. Tal processo tem sido conhecido como universitarização e consiste na elevação da formação do professor para o nível superior. Sabemos que no México essa exigência já ocorre há mais tempo. 
Sim, eu acho que em muitos países esses movimentos estão presentes na formação dos profissionais da educação. Sempre houve a necessidade de atualizar, de profissionalizar, porque a profissão docente começou, no México e em outros países, com pessoas que não eram qualificadas em nível superior. No México, foi uma profissionalização que começou muito cedo na história da educação, desde quando se tem formação inicial em nível médio. Não era uma formação universitária, mas já era profıssional, pois eram as Escolas Normais que formavam os professores desde o século XIX. Lá iniciaram essa formação sistematizada com currículo, ${ }^{7}$ com validação oficial de nível médio-superior. Depois houve a necessidade de universitarizar. Muitos professores exerceram a profissão sem terem cursado a Escola Normal. As Normais existiam antes da Revolução Mexicana, mas com ela houve a necessidade do Estado de promover a educação e certas ideias sobre o mexicano, o nacional, além de universalizar os conteúdos da educação e levar às comunidades a palavra escrita e a leitura. Foram inúmeros os professores que exerceram a docência sem terem estudado nas Escolas Normais. Criouse então um sistema de atualização para professores, que se profissionalizavam durante os feriados, as férias e os finais de semana em um grande instituto, o Instituto Federal de Capacitação do Magistério. Esse instituto teve muito peso na formação de professores e veio a constituir uma tradição de formação docente muito forte no México. Depois da Revolução, houve também um movimento, originado na Secretaria da Educação Pública, que levava às escolas contribuições para os professores que não tinham formação. Eram as chamadas missões culturais, ocorridas nos anos 1930 e 1940. Eram grupos que iam às escolas com pessoal especializado em diferentes áreas, tais como a pedagogia, a didática, o cultivo das hortas escolares e o trabalho com as comunidades, não somente com as crianças

7- Os termos plano de estudo e currículo são usados como sinônimos. na escola, mas também com os jovens e com os adultos. Essas missões constituíram o que poderíamos definir como as primeiras formas de atualização ou capacitação de professores, mas levadas às escolas, por todo o país. Isso durou muito tempo, e inclusive me parece que algumas ainda funcionam em alguns estados. Havia a possibilidade, que nesse momento coincidia com uma disposição política, de se estar bem próximo às escolas e apoiar o trabalho que ali se realizava. Esse foi então outro ramo que me parece ter auxiliado na construção do patrimônio histórico-cultural da formação dos professores no México. Depois, esse instituto ao qual me referi, que profissionalizava em aulas normais, nas férias e nos feriados, cresceu muito, pois havia muitos professores nessa situação. Ele atuou por várias gerações e as Normais continuaram crescendo. Chegou um momento em que as Normais já formavam os novos professores e não havia mais a necessidade de profissionalizar, embora ainda houvesse uma grande quantidade de professores sem formação em nível superior. Por isso, algum tempo depois se constituiu a Universidade Pedagógica, que representava a aspiração de grandes setores do magistério de ter um espaço universitário próprio de profissionalização. Esse era também um projeto do sindicato de professores, que historicamente tem, no México, vínculos fortes com o Estado, sendo um dos sindicatos em que o Estado se apoiava para promover e introduzir suas políticas educativas em todo o país. Assim, a Universidade Pedagógica Nacional foi um projeto em que convergiram diferentes interesses. Há uma sede central na Cidade do México, além de unidades em diferentes estados do país. Depois, entre os anos 1980 e 1990, com a federalização que se denominou descentralização educativa, o Estado mexicano delegou aos estados a responsabilidade pelas instituições; agora, são os estados que fazem a gestão da educação nos diferentes níveis e propõem programas, mas com recursos do governo central. As Universidades Pedagógicas ficam, assim, a cargo dos estados e já não 
mais do governo central, embora a unidade central da Universidade Pedagógica continue estabelecendo as normas acadêmicas, ou pelo menos as mais fundamentais. Esse processo de descentralização, muito estudado no México, não foi homogêneo, nem sequer semelhante entre os estados.

Em 1984, houve uma reforma nas Normais, que passaram a ser instituições de ensino superior, embora não tenham se transformado em universidades. As Normais Superiores são as que formam os professores de ensino médio ou de secundária, como chamamos no México. Esses professores são aqueles especializados em disciplinas, como biologia e matemática. No México, as Escolas Normais oferecem licenciaturas em educação primária, educação pré-escolar, educação especial, educação física e outras áreas. As Normais Superiores são responsáveis pelas licenciaturas para os professores da escola secundária (ensino médio) nas diversas disciplinas. Todas têm o nível de educação superior e aqueles que nelas ingressam passam por um bachilerato, que, para nós, é a educação média superior, depois da secundária.

\section{Quanto tempo leva essa formação?}

Acredito que são dois ou três anos de preparatória e depois quatro ou cinco de nível superior; no caso da formação de professores, são quatro anos. Os que concluem as Escolas Normais recebem o título de professor licenciado em pré-escolar, educação primária ou educação especial, entre outras, conforme expliquei.

Hoje, a maioria dos professores tem o nível superior, pois a Universidade Pedagógica profissionalizou nesse nível todos os que já atuavam, enquanto os novos professores ingressavam nas Escolas Normais.

\section{E isso aconteceu em que época? Anos 1980?}

Sim, porque em 1984 a Normal se transformou, passando sua formação para quatro anos. Por algum tempo, a formação de professores era feita apenas pelas escolas públicas e ninguém mais podia fazê-lo, pois se tratava de uma profissão de Estado. Há um historiador muito bom no México que se dedicou à história da educação (ARNAUT, 1996). Esse autor, ao descrever os processos de mudança na formação de professores, analisa o modo como, em algum momento, dentro da política educativa e de governo, as universidades obtiveram sua autonomia. No debate travado entre as comunidades universitárias e o Estado mexicano, as universidades conseguiram autonomia, o que foi questionado por alguns governantes, já que as Normais não eram autônomas. Arnaut escreve que as universidades podiam ser autônomas, mas a formação de professores não, pois nas mãos destes está a educação pública, que é de responsabilidade estatal. Por esse motivo a formação dos professores não poderia ser autônoma, devendo estar ao encargo do Estado. Tal ideia diz muito sobre como era importante, naquela época, conservar o caráter público e estatal da educação. Hoje existem Normais privadas, mas isso começou há pouco tempo e agora essa modalidade de formação está aberta ao mercado. Ela é um mercado, como vocês dizem. ${ }^{8}$ Temos muitos professores egressos das Normais particulares, as quais, supõem-se, devem ater-se aos planos de estudo oficiais.

Retomando um pouco a história, a ampliação da Universidade Pedagógica nos anos 1980 garantiu acesso ao ensino superior à maioria dos professores em exercício. Depois dos anos 1990, ela começou a ser reduzida e sua função passou a ser, principalmente, a de oferecer pós-graduação. Abriram-se alternativas de formação de professores não apenas no ensino fundamental, básico e pré-escolar, mas também em questões interculturais, relacionadas à tecnologia e a outros temas emergentes. A interculturalidade passou a ser um tema, muito embora a questão da educação indígena seja algo presente há bastante tempo no México.

8- A entrevistada refere-se a uma pesquisa desenvolvida no âmbito de um Projeto Temático da FAPESP (SOUZA; SARTI, 2008). 
Então, o que a Universidade Pedagógica fez foi dar abertura à formação de professores em diversas áreas que foram emergindo, inclusive em temas que parecem não ter relação direta com a educação. Os cursos de pós-graduação são uma questão à parte.

Essa é uma discussão que agora se tem também no Brasil: a do mestrado profissional.

Sim. Afınal, que alternativas tinham os professores de cursar a pós-graduação? Foram criadas pós-graduações mais acessíveis, mais flexíveis, pois os cursos de mais exigentes não tinham a possibilidade de receber os professores.

Mas imaginamos que no México também seja como aqui. A pós-graduação é um programa que, a princípio, visa à formação do pesquisador e do docente no ensino superior, o que não é o caso dos professores da escola básica. Alguns argumentam que a pós-graduação poderia ser mais adequada às necessidades do professor que não tem o objetivo de ser pesquisador ou professor do ensino superior, mas sim busca um processo de formação, de desenvolvimento profissional.

Claro, de desenvolvimento profissional dentro do seu campo de trabalho, que é o ensino. Muitos dizem: "quero continuar estudando, mas quero ser professor, e não pesquisador”. Porém, não há essa possibilidade, já que todos os cursos de pós-graduação visam à pesquisa. Quem desenha os cursos de pós-graduação quer formar pesquisadores. Eu assessorei um plano de estudos para um mestrado voltado à profissionalização, junto a uma Escola Normal, mas acabaram fazendo algo voltado para a pesquisa. Pergunto a eles: "Por que tanta ênfase na pesquisa? Por que não um maior conhecimento, um aprofundamento de tudo o que nós já sabemos sobre a docência e o ensino?". Eles me escutam, pois eu os estou assessorando, mas a tendência é focar na pesquisa-intervenção, na pesquisa etnográfica, e os professores se sentem obrigados a fazer isso. Então, esses são planos de estudo que não são academicamente muito fortes, porque se vai trabalhar com professores que não têm tempo para estudar, apenas nos finais de semana. São planos de estudo aprovados pelo governo do Estado, que pensa: "Tudo bem, vamos ter um curso de pós-graduação”. Aprovar cursos é bom para o governo do Estado, mas, academicamente, não há especialistas que avaliem anteriormente esses programas de pós-graduação quanto à sua qualidade.

Em sua opinião, as dificuldades em se construir um currículo de pós-graduação voltado à docência, ao aperfeiçoamento da docência, decorrem do quê? Nós, na universidade, temos esse saber já construído?

Creio que isso decorre de múltiplos fatores. Há uma tensão na academia que se relaciona aos cursos de pós-graduação. As pós-graduações têm maior história nas áreas das ciências duras, que formam os cientistas. Na área da educação, o que se fez foi imitar esse paradigma de formação em pós-graduação, que deve sim, obviamente, formar cientistas e estudiosos da educação, mas que, nesse caso, por ser uma profissão que demanda atualização, como todas, não termina com a formação inicial. Só que outros profissionais têm espaços para continuar se formando academicamente, sem necessariamente se transformarem em cientistas. Na área da profissão docente, há no mínimo dois pressupostos: um deles é de que os cursos de pós-graduação são para formar cientistas, pesquisadores; o outro é o de que aquele que realiza a docência não precisa saber tanto, pois já sabe o que tinha que saber. Trata-se de uma construção social de uma visão sobre o ensino e sobre a docência como algo não tão difícil: "Por que você entraria em um curso de pós-graduação para saber mais da docência? Você já estudou pedagogia, você estudou sociologia da educação!".

Teria isso a ver com a ideia de que se aprende pela experiência, de que essa aproximação 
com a experiência forma e de que não é preciso saber muito?

Pode ser, não sei... Afınal, menosprezase muito essa formação prática. Eu acredito que tem mais a ver com uma ideia da docência como algo simples. Ou seja, um médico precisa continuar se atualizando porque a medicina é associada a conhecimentos muito complexos e em constante desenvolvimento; um engenheiro civil precisa continuar sabendo sobre a produção dos novos materiais, de novos desenhos. Todas essas profissões são tidas como complexas para justificar que sejam criados cursos de pósgraduação que não estejam voltados para a produção científica. Os médicos, por exemplo, vão a congressos e não têm que ser cientistas.

\section{São profissionais.}

Profissionais da medicina que não necessariamente fazem pesquisa. São profissionais que têm desafios de resolução cotidiana. Mas o que o profissional da educação, da docência, tem que saber mais? Será que se produzem novos conhecimentos sobre a docência? Essas concepções me parecem muito complicadas, pois são construções históricas e quase não nos é possível imaginar um curso de pós-graduação em educação que tenha conteúdos, produtos de pesquisas, mas que permita ao profissional da docência saber mais sobre a própria docência. Acredito que essa é uma das razões. A outra, à qual você se referiu, é que nós não sabemos bem como fazer. Nós pretendemos conduzir o professor por determinado caminho, definindo conteúdos que ele deve aprender, pois achamos que esses são os mais importantes. E não há um consenso acadêmico quanto ao que seria a formação de um bom professor. Alguns argumentam que é necessário mais didática; outros, maior densidade teórica. Para mim, há outras coisas importantes na formação do professor, como a produção de conhecimento sobre a escola cotidiana, sobre o ensino cotidiano, sobre a conformação histórica da profissão docente. Há várias coisas que podem ajudar o professor a simplesmente saber mais, a ampliar seu conhecimento sobre a docência, sobre a escola e os processos de escolarização. Muita coisa está sendo produzida o tempo todo na pesquisa, mas embora isso circule entre nós, não sabemos como traduzir aos professores. Pretendemos levar as teorias e os produtos da pesquisa tal qual eles são elaborados na academia. Depois dizemos: "Não compreendem, não leem!”.

Sua fala se aproxima do que afirma AnneMarie Chartier (2007) sobre como os textos e os discursos circulam de modo diverso na academia e na escola.

Totalmente. Inclusive escrevi um livro em coautoria com uma colega que foi publicado recentemente: Saber enseñar, un trabajo de maestros (MERCADO; LUNA, 2013). Foi um trabalho árduo, pois não se trata de uma produção para a academia; vem daí, mas tem outra linguagem, outra forma de falar com o professor.

Esse é um tema sobre o qual gostaríamos de conversar. Como escrever para os professores?

Digo a vocês que isso é um ofício que precisamos aprender, que não nos é dado pela pesquisa. Não se aprende a escrever para o professor por ser pesquisador. Acredito que é justamente o contrário: por sermos pesquisadores, desenvolvemos características que podem nos afastar da possibilidade de escrever para o professor. A pesquisa alimenta, dá a possibilidade escrever algo, mas não nos forma para fazê-lo. Há inúmeros exemplos. 0 DIE nasceu produzindo livros de texto para a escola. 0 diretor, um biólogo, não era a pessoa mais indicada para fazê-lo, pois sabia sobre biologia, mas não sobre como falar com o professor. Não o sabia pois nunca esteve na escola, nunca foi falar com os alunos. Seu pensamento não foi formado para saber o que é ser um professor, o que é essa profissão, qual 
é sua condição de trabalho. Então ele fala da perspectiva da biologia, apenas. A inovação no DIE foi que antropólogos, biólogos, físicos e, enfim, especialistas em disciplinas específicas tinham, de alguma maneira, proximidade com a escola e com os professores, ou algum interesse. Tinham uma postura avaliativa, mas também uma abertura intelectual que fez com que eles construíssem seus textos e os levassem às escolas, perguntando depois para o professor: “0 que você achou?”. Daí começou o que denominamos etnografia, pois vinha de pesquisadores que se interessavam por saber o que pensavam os professores.

O DIE nasceu com esta raiz: a partir dos livros nas escolas e do interesse por saber o que acontecia. Era um departamento que fazia livros, e não uma instituição de pesquisa, mas estavam ali pessoas que se interessavam em pesquisar. 0 departamento nasceu dessa forma e nós acumulamos muita experiência em elaborar materiais para professores e, posteriormente, para os cursos comunitários. Nessa experiência, aprendemos que os especialistas nas disciplinas não conseguiam elaborar livros de textos que os professores compreendessem e que dessem sentido ao seu trabalho, ou que os ajudassem a dar sentido. Então, os físicos, os biólogos e todos os demais, sempre que produziam seus livros sozinhos, não conseguiam fazer com que estes correspondessem ao que queriam transmitir. Escrever para os professores tem vários níveis; um deles é relacionado ao trabalho dos especialistas de cada disciplina, mas é preciso que haja também alguém da pesquisa educativa.

\section{Que conheça a escola...}

Que conheça a escola e que saiba escrever para os professores. Outra forma é a escrita que vocês estão pensando: para a formação dos professores, em si; para que o professor leia e estude, de forma coletiva.

Essa é um pouco a função do livro que vocês escreveram.
Sim. Esse livro teve, no fundo, a mesma dificuldade: como escrever para um professor? De que modo escrever sem pretender dizer como fazer; sem pretender dizer ao outro "você não sabe, eu sei”? Não se trata de um manual. 0 manual é algo que diz como se deve fazer. É claro que a editora quer que nós façamos um manual, ou algo mais próximo de um manual. Os editores dizem: "Está boa a ideia de vocês de não fazer um manual assim, estrito; mas não vai ter algo de didática, para que o professor se forme, para ensinar-lhe algo?”. Então nós temos que negociar, sobretudo eu. No meu caso, o livro não é nem de espanhol, nem de matemática, nem de ensino de nenhuma área; é do ensino, e por isso tem esse título. Eu tive que brigar pelo título com a editora, porque eles queriam - e conseguiram - acrescentar um subtítulo - propostas, sugestões, não lembro ao certo. Mas fiz questão de manter a expressão um trabalho de professor. Essa expressão parte da orientação de que o professor sabe ensinar, mas que nós podemos contribuir com algo, o que pode vir, inclusive, de outros professores.

Para desenvolver esse tipo de escrita, foi necessário retomar o conhecimento que tínhamos sobre a escola e os professores - não apenas do contato com eles, mas também de leituras e pesquisa sobre eles -, considerar o que eles sabem (como imagino ser esse professor, como sujeito histórico coletivo) e entrelaçar tudo isso na escrita. Acho que é o que permite que você se aproxime de uma linguagem acessível, próxima, com sentido para o professor. Mas isso só saberei depois, quando o livro estiver na escola e eu conseguir falar com eles. Penso que esse é o desafio de uma escrita para professores, porque há essas vozes - seguindo Bakhtin (1989), o dialogismo -: a voz do professor, a do pesquisador, a do formador. Quando se concebe o professor como sujeito histórico, diverso, você consegue falar com ele não como alguém inferior ou superior, mas como alguém que decide o que faz. Você diz algo, mas sem um caráter prescritivo. No livro, mostro vídeos com cenas de sala de aula 
que foram bastante editadas. Os professores, quando olham a atuação de outros colegas, tendem a avaliá-los: "Ele não fez isso, ele não sabe!". Então, tive que editar muito e fazer comentários, em várias passagens, lembrando sempre que se trata de um material que não se pretende ser um modelo, mas apenas provocar uma reflexão. Comecei dizendo que essa é uma dívida que o pesquisador tem com o professor: não basta escrever artigos em periódicos. Pensamos que é a mesma coisa, mas você leva o artigo e o professor não vai ler. Eu costumava deixar artigos nas escolas, e até levei minha própria tese de doutorado; depois voltei para ver o que eles tinham achado e eles não haviam lido: era chato! Alguns podem se interessar, mas eles estão muito ocupados, e é preciso que haja um espaço de formação, com outro tipo de trabalho. Esse livro é uma derivação do meu livro sobre saberes (MERCADO, 2002), mas não está escrito da mesma forma.

Aproveitando que estamos falando sobre escrita, sobre como escrever para professores, este é um tema que o qual temos nos ocupado mais recentemente: a investigação dos processos de escrita, em várias modalidades, utilizados nos programas especiais de formação de professores. Há, por exemplo, os memoriais que convidam os professores a retomarem sua própria história a partir de um tipo de escrita autobiográfica. Na França, os IUFMs (Institutos Universitários de Formação de Professores) têm uma prática de escrita de memoriais de formação que difere da escrita autobiográfica que temos no PEC. Há vários tipos de escritas: a escrita de trabalhos monográficos, a escrita de registro das vivências do estágio. Gostaríamos que você falasse um pouco tanto da escrita para o professor, quanto da escrita do próprio professor.

Eu tive experiência com vários processos relativos a essas diferentes modalidades de escrita usadas em vários países, e acho que depositamos muitas expectativas em cada tipo de escrita. Por que pedimos aos professores que escrevam? - eu me pergunto. Porque temos hipóteses a respeito de que essa escrita pode ser algo bom, por algum motivo. Eu não tenho respostas. Pode ser que para alguns professores seja bom. Eu gostaria de saber o que pensam quando escrevem, o que a escrita lhes agrega ou acrescenta. Quando uma pessoa escreve sua autobiografia ou relatos autobiográficos, está cumprindo diferentes funções para ela mesma: pode ser que haja um alívio emocional com benefícios terapêuticos. Por exemplo, durante uma crise, escrever sobre o que está acontecendo pode ter efeitos psicoterapêuticos para alguém, ainda que não sejam explícitos; para outra pessoa, isso pode não ocorrer. Temos a hipótese de que essa escrita pode servir para a autoformação, mas eu gostaria de saber se ela realmente tem alguma função formativa para os professores. Eu acho que é bom escrever. Existem professores que, pelo seu próprio trabalho, gostam muito de escrever, mas produzem escritos que não conhecemos, que não são públicos. Tais escritos são os que eu gostaria de conhecer, mais do que os textos que nós promovemos como formadores. Essa escrita, porém, é quase inacessível; só em um trabalho etnográfico muito fino se consegue ter acesso a ela.

Retomando a pergunta: será que podemos ter algum acesso a coisas como os saberes docentes por meio dos escritos? Duvido muito, pelo menos em minha concepção de saberes: saberes como postos em práticas, como ações, como ações com sentido, como construções de conhecimentos docentes - e não quaisquer saberes (MERCAD0, 2002). Certamente existem saberes num escrito, mas não sei se esses são os saberes docentes de que estou falando. Há uma reflexão sobre os saberes que, como seres humanos, construímos para viver no mundo. Mas não se pode falar de saberes docentes. Penso que a escrita dos professores pode ser muito valiosa para a formação. Há autores e trabalhos que se valem de narrativas de professores em que podem estar envolvidas muitas áreas, desde a história, a micro-história, a autobiografia e 
essa dimensão mais psicológica ou afetivoemocional, bem como a literatura. Penso que tais narrativas de professores podem servir a muitos propósitos, mas não sei se servem para a formação ou para a autoformação.

De alguma forma há certo modismo na utilização de escritas de cunho autobiográfico em processos de formação.

Sim, há. É como se essa abordagem fosse uma mina de ouro, a chave de enigmas sobre a formação. Há expectativas excessivas acerca disso. Não duvido que a escrita aporte elementos para diversos tipos de análises. Acho que ela pode ser um campo muito fértil, muito produtivo de conhecimento sobre nós, e não só sobre os professores. Por que os médicos não escrevem? Penso que deviam escrever.

De alguma maneira, isso tem a ver com o fato de nós, professores tanto do ensino superior quanto da educação básica, lidarmos com a escrita em nossa prática; o médico não lida com a escrita. Na etnografia e em todos esses estudos que você tem feito sobre a docência, sobre a prática dos professores, você se deparou com professores que fazem registros próprios?

Temos grande dificuldade em conceber o que realmente escrevem os professores e o que leem. Essa é uma dificuldade epistemológica nossa, porque não concebemos como eles aprendem coisas e desenvolvem seu próprio conhecimento diferentemente de nós - ou dos médicos, por exemplo, que pegam um livro na estante no momento da consulta para explicar um diagnóstico. Há aí uma relação ativa com os livros, porque no momento em que o médico mostra o livro, ele não precisaria fazê-lo, ou seja, não se trata de um instrumento para curar o paciente. A escrita e a leitura, para o médico, são construções próprias que ele usa em certas circunstâncias, e que não são comuns, não consistem em um instrumento, mas são outra coisa. Essa escrita dos professores que ficou pouco acessível a nós - porque, volto a dizer, é uma prática privada - é muito frequente. Os indícios que tenho em meu trabalho são estes: "Ah! Eu tenho um livro de poesia, eu faço poesia”. Vários professores fazem poesia, mas é muito difícil que mostrem. E eles também produzem outros escritos, como memórias, mas não no formato acadêmico de memórias.

Certa vez, quando eu visitava uma Normal rural do México - que foi muito combativa, de esquerda e radical, tendo à época 60 ou 70 por cento de indígenas -, um professor me entregou um texto impresso de aproximadamente 60 páginas, na intenção de que eu lesse e depois comentasse. Eu não sabia o que ele queria que eu fizesse ou que finalidade tinha aquela escrita. Era como uma memória dessa Normal, famosa no México por sua combatividade. Eles estavam sofrendo repressão pelo governo e aquele professor era parte dessa escola. Então eu lhe perguntei: "Professor, isto é um livro? o que espera que eu faça?". "Faça o que você quiser", ele me respondeu. Não entendi nada. Então levei o impresso para minha casa para ler e depois dar um retorno. 0 texto continha sua história, a história da escola e do movimento social contra o Estado, que sempre buscou subjugá-la, sem sucesso. Parecia um livro escrito ao longo de anos, mas ele não queria que ninguém soubesse: "É só para você". 0 que quero ressaltar é que essa escrita que o professor faz durante toda sua vida é pode ser de muitos tipos. Acho que a maioria trata de memória de coisas que se passaram em suas vidas de professores. Desses escritos, destaco duas coisas: quase todos os professores que conheci, que são muitos, escrevem, mas suas escritas são totalmente privadas. Acho que eles conseguem, sim, escrever em um espaço de formação em que se consiga construir uma relação, um espaço de confiança. Mas de seus escritos originais, feitos por sua própria iniciativa, poucos vêm à luz. Uma hipótese que me ocorre é que os professores têm, mais do que outros profissionais, grande necessidade de expressar o que se passa em suas histórias. Como 
a docência é um trabalho tão desvalorizado socialmente, seus escritos ficam privados. Parece que não têm valor para ninguém, porque é uma profissão muito criticada atualmente no México e foi assim por anos: "Os professores não fazem, os professores não pensam, os professores não ensinam, estão na rua”. Eu entendo que, antes, no México, quando a profissão docente era mais valorizada, eles mostravam mais. Lembro que, quando eu era jovem, havia professores que liam seus poemas em algumas ocasiões, principalmente nos círculos de estudo, que eram muito tradicionais. Depois isso desapareceu e toda a escrita se tornou privada. Se o espaço de formação consegue constituir-se num lugar onde os professores podem expressar tudo o que eles fazem, acho que isso seria saudável.

Nós também gostariamos de conversar com você sobre esse movimento de aproximação entre a formação de professores e a escola de educação básica. Essas discussões estão relacionadas à histórica crítica feita à formação mais teórica e pouco prática dos professores.

Voltarei depois ao tema da prática, da formação prática. Antes gostaria de retomar as mudanças ocorridas recentemente no México. Em setembro de 2012, introduziu-se uma nova reforma, uma mudança no currículo. Houve muita insistência por parte do Estado e dos grupos acadêmico-políticos, que desenharam a reforma para que a formação fosse ampliada para cinco anos. De fato, eles já tinham o plano de cinco anos no currículo, mas houve muita discussão, resistência e oposição, ainda que essa não tenha sido uma discussão muito aberta. É o que digo no artigo publicado na revista da ABRAPEE (MALDONADO, 2010). Não foi uma discussão pública, mas os grupos que participaram conseguiram que a formação ficasse com quatro anos. A discussão não dizia respeito apenas à duração, mas também questionava se a formação do professor devia continuar nas Normais ou passar às universidades, debate este sempre presente.
Dizia-se: "As Normais são coisas do passado, agora é preciso universitarizar". Mas as Normais continuaram e não se conseguiu passar essa formação para a universidade. Então, minha opinião é a de que, em muitos países nos quais se fez a mudança das Normais para a Universidade, os problemas-chave da formação não foram resolvidos. Um deles é a relação entre formação teórica e prática. Em toda revisão de literatura que se faça em qualquer país, está presente a discussão sobre a melhor proporção de prática e de teoria, sobre qual porção do currículo a prática deve ocupar e sobre qual será a relação entre essas duas dimensões. E esse debate continua. Ainda que a formação esteja na universidade, muitos investigadores estadunidenses se interessaram em estudar o que chamamos de distância entre a formação universitária e a prática na escola básica, tratando de encurtar essa distância de mil maneiras, desde a investigação-ação, em que os professores universitários que fazem pesquisa vão à escola básica e fazem intervenção e pesquisa participante, supondo incorporar os professores da escola básica na pesquisa. Assim, nessa colaboração, já se resolveria a falta de proximidade entre professores universitários e a escola básica. Mas há muitos estudos que analisam e contam que não foi possível, por esses meios, estabelecer uma maior relação para a formação de professores.

Mas existia uma relação formal entre as Normais e as escolas? Existiam figuras docentes nesses dois espaços, nas Normais e nas escolas?

Havia professores de técnica de ensino na Normal que acompanhavam um pouco, mas não havia uma regulamentação para tal acompanhamento. Esse professor de técnica avaliava o estudante que desenvolvia as propostas que ele havia ensinado, as quais se concentravam, principalmente, na elaboração de material didático. Produziam-se muitos materiais didáticos e essa era a parte 
fundamental da formação para o ensino. Então, o professor da escola básica simplesmente tinha que aceitar que esse estudante fosse um dia da semana dar uma aula. Mas também as Normais tinham uma escola anexa, as "Escolas de Aplicação”, que eram locais para os estudantes praticarem, observarem. Eram escolas tão especiais, tão observadas, tão próximas às Normais, que alguns de seus professores acabaram constituindo o pessoal docente das Normais. Muitos professores das Normais, ainda nos anos 1960, haviam sido professores de educação básica e tinham experiência no ensino daquilo que hoje ensinavam aos seus alunos. Isso desapareceu no Plano de 1984, que foi muito centrado na teoria e demandou profissionais como sociólogos, historiadores e psicólogos. Havia estágio, sim, em que os professores iam até a escola com os estudantes, numa matéria que se chamava Laboratório de Docência. Na escola Normal, no Plano de 1984, essa prática era usada a título de análise numa perspectiva de formação de professores investigadores, embora não explicitamente. As matérias ministradas eram etnografia e investigação qualitativa, e todas as abordagens de pesquisa tinham que ser ensinadas. Foi quando comecei a trabalhar com as Normais, porque elas precisavam de pesquisadores que ensinassem seus professores a pesquisar. Aí desenvolvi mais intensamente meu trabalho sobre formação de professores. Eu falava para eles: "os professores não têm que saber etnografia". "Mas no currículo diz que temos que ensinar os alunos a observar os professores", respondiam eles. Publiquei alguns trabalhos afırmando que assim não estávamos formando docentes, nem pesquisadores (MERCADO, 1994). Foram anos e anos de trabalhos e seminários com professores de Normais que realizavam seus estudos etnográficos com todos os preconceitos a respeito dos professores de educação básica: "Eles não sabem disso, não sabem daquilo", diziam. Os estudantes iam para as escolas com um olhar avaliativo, e eu usava diversos materiais para trabalhar com os professores, explicando o que era e o que não era etnografia. Foram muitas discussões procurando deixar claro que formar professores e formar etnógrafos são tarefas diferentes. E isso tudo me levou no caminho dos estudos sobre a formação inicial. Os estudantes iam para a escola básica e diziam aos professores: "Eu sou pesquisador, venho aqui fazer etnografia, venho observar". Era como dizer "Vocês não são licenciados", pois isso foi justamente quando os professores ficaram desprofissionalizados. "Nós somos licenciados e vocês não são. Vamos analisar o que vocês fazem." Era tudo tão avaliativo, que as escolas básicas começaram a fechar as portas para a prática. Foi um grande conflito entre a formação nas Normais e a escola básica. No Plano de 1997, foram feitas várias alterações a partir dessa experiência com a finalidade de fortalecer a prática. Desde o primeiro semestre os estudantes iam à escola não para ensinar, só para conhecer. No sétimo e oitavo semestres, que eram os períodos finais, eles ficavam o ano todo em uma turma. Assim, esse eixo de aproximação à prática era feito ao longo do curso, até que, ao final, os estudantes permaneciam durante todo o ano na escola básica. Ao mesmo tempo, iam à Normal e aos seminários. A mudança que ocorreu na formação durante esse Plano não era só em relação ao tempo passado na escola, mas à ideia de analisar na condição de aprendizes da docência, e não como pesquisadores. A dissertação de Nancy Hilario (2011), que orientei, analisa melhor esses processos.

\section{E nesse Plano surge a figura do tutor dentro da escola básica?}

Sim. 0 currículo previa um tutor na escola básica e um assessor na Escola Normal, formando um triângulo com o aluno.

\section{Isso foi no Plano de 1997?}

De 1997 a 2012. Em setembro de 2012, o governo de direita que assumiu o poder 
desde 2006 introduziu mudanças alinhadas ao neoliberalismo na educação. 0 interesse era mudar todos os currículos desde a escola básica, organizando-os por competências. Então, as Normais não só assumiram as competências, como eliminaram boa parte da prática. Ou seja, o que se fazia era semelhante à residência, porque eles ficavam na escola com o professor titular. Nesse modelo, eu entendia que era necessário definir melhor a figura do tutor, pois ele é um profissional que tem um trabalho como professor e também uma responsabilidade na formação dos estudantes da Normal, observando-os e apoiando-os, mas que não recebe um pagamento por esse trabalho. Foi estabelecido um perfil para tal profissional: ser um bom professor, ser bemvisto pela escola. 0 assessor tampouco recebe um pagamento extra e tem mais trabalho, porque dá aulas e acompanha os estudantes. Cada um tem cerca de oito estudantes para acompanhar nos estágios, devendo ir às escolas e participar da elaboração, pelos estudantes, de seu trabalho de conclusão de curso. Assim, esses dois professores têm responsabilidades agregadas ao seu trabalho cotidiano.

Nas investigações que realizei e orientei, fizemos etnografia com estudantes das escolas Normais, com tutores e com assessoras, e encontramos coisas maravilhosas, coisas que contradizem e questionam as afırmações dicotômicas de que as práticas de estágio ou são tudo ou não são nada. Encontramos vários processos formativos nos quais ocorrem situações em que os estudantes vão transformando suas ideias acerca do que é a escola, do que é o ensino. Assim que chegavam à escola, diziam: "Os professores não têm relações harmônicas, não se comunicam tanto. Deveriam fazer tudo como um coletivo". Há aí uma visão idealizada, uma visão romântica de como deveria ser a escola, com todos de acordo, todos caminhando juntos. Não existe isso em nenhum lugar. No início, quando entravam nas salas de aula para apoiar o tutor, falavam assim: "0 professor é muito autoritário; eu não vou fazer assim, eu não vou gritar”. Depois eles descrevem, não somente nas entrevistas, mas também nos encontros que os professores organizam, como eles próprios agiam da mesma maneira: "Ah! Quando comecei a dar aula, os meninos não me davam atenção e eu gritava. Depois fiquei doente e a professora me dizia: 'Você não tem que gritar, porque você vai adoecer". Assim, os relatos dos estudantes mudavam bastante e eles iam aprendendo, inclusive com aqueles professores que se valiam da ajuda dos estagiários para fazer outras coisas. Isso era muito negativo, mas entre o negativo e o não negativo, vai havendo um processo de mudança. Não que todos vão ficar felizes com o que acontece, mas mudam e esses são processos formativos.

No Chile e no México, os pesquisadores falavam: "Como os estudantes vão lidar com um professor ruim neste estágio, nesta residência? Eles vão ensinar coisas ruins!". Claro! Assim é a vida! Mas não vão ficar só com coisas ruins, afınal, entre os médicos com quem os estudantes vão fazer residência, há médicos ruins e outros que não são ruins, e eles têm que aprender. Não estou justificando a existência de professores ruins, mas essa diversidade é o que compõe a escola. "Então não deveríamos escolher, selecionar os melhores para serem tutores?" - perguntavam os professores chilenos e mexicanos. Ou então: "Como podemos saber quais são os melhores? Vamos fazer um concurso? E como se isso dará?”. Há muitas questões envolvidas e penso que deveríamos abordá-las nos seminários da universidade, junto com os estudantes.

Então agora não existe mais essa figura do tutor na escola?

Existe, mas agora só durante um semestre. Isso muda toda a ideia de acompanhar um ano escolar de uma mesma turma de meninos, cujos processos você conhece. Seriam necessárias avaliações com estudos de meio. Se não se fazem estudos, como é possível aperfeiçoar? Há agora uma confusão, uma rejeição, pois a essa reforma se agregou a reforma trabalhista para 
todos os professores, que precisam ser avaliados por competências. Há uma rejeição forte pelos professores, e eu acredito que existem argumentos pedagógicos, acadêmicos e de todo tipo contra a introdução da reforma. Há muitas coisas que podiam se resolver sem uma reforma total. Afinal, são 15 anos em que coisas aconteceram, mas apagaram tudo. A reforma apagou tudo.

\section{Referências}

ARNAUT, Alberto. Historia de una profesión: los maestros de educación primaria en México, 1887-1994. México: Centro de Investigación y Docencia Económicas, 1996.

BAKHTIN, Mikhail. Teoria y estética de la novela. Madrid: Taurus, 1989.

CHARTIER, Anne Marie. A ação docente: entre saberes práticos e saberes teóricos. In. Práticas de leitura e escrita: história e atualidade. Belo Horizonte: Ceale/Autêntica, 2007. p. 185-207.

HILARIO, Nancy C. Procesos formativos en las prácticas de preservicio de estudiantes de magisterio: entre la normal y la primaria. Tesis (Maestra en Ciencias con la Especialidad en Investigaciones Educativas) - Centro de Investigación y de Estudios Avanzados Del Instituto Politécnico Nacional, México, 2011.

MALDONADO, Ruth Mercado. Un debate actual sobre la formación inicial de docentes en México. Revista Psicologia Escolar e Educacional, v.14, n. 1, p. 149-157, jan./jun. 2010.

MERCADO, Ruth. Formar para la docencia: reto de la educación normal. México: Universidad Futura; Universidad Autónoma Metropolitana, 1994.

Los saberes docentes como construcción social: la enseñanza centrada en los niños. México: Fondo de Cultura Económica, 2002.

MERCADO, Ruth; LUNA, Maria Eugenia. Saber enseñar, un trabajo de maestros. México: Editorial SM; CINVESTAV, 2013.

ROCKWELL, Elsie (Coord.). La práctica docente y su contexto institucional y social. México: DIE-CINVESTAV, 1980. (mimeo)

ROCKWELL, Elsie; MERCAD0, Ruth. La práctica docente y la formación de maestros. In: La escuela, lugar del trabajo docente. 3. ed. México: DIE-CINVESTAV-IPN, 1999. Descripciones y debates [1986]

SOUZA, Denise Trento R. de; SARTI, Flavia M. Programas especiais e o mercado da formação docente: dispositivos, produtos e práticas de consumo. Projeto de pesquisa, FAPESP, 2008.

\section{Principais trabalhos da autora}

\section{Livros:}

MERCAD0, Ruth. La educación primaria gratuita, una lucha popular cotidiana. 2. ed. México: Departamento de Investigaciones Educativas del Centro de Investigación y de Estudios Avanzados del IPN, 1985. (Cuadernos de Investigación Educativa, n. 17.)

. Formar para la docencia: reto de la educación normal. México: Universidad Futura; Universidad Autónoma Metropolitana, 1994.

El trabajo docente en el medio rural. México: DIE-CINVESTAV IPN, 1999. 
MERCADO, Ruth. La implantación del plan 1997 de la licenciatura en educación primaria. México: Subsecretaría de Educación Básica y Normal, Dirección General de Investigación Educativa, 2000.

Los saberes docentes como construcción social: la enseñanza centrada en los niños. México: Fondo de Cultura Económica, 2002.

\section{Livros em parceria:}

MERCADO, Ruth; LUNA, Maria Eugenia. Saber enseñar, un trabajo de maestros. México: Editorial SM e CINVESTAV, 2013.

ROCKWELL, Elsie; MERCADO, Ruth. Dialogar y descubrir: la experiencia de ser instructor. México: Consejo Nacional de Fomento Educativo: DIE-CINVESTAV-IPN, 1990.

La escuela, lugar del trabajo docente. 3. ed. México: DIE-CINVESTAV-IPN, 1999. Descripciones y debates.

\section{Capítulos de livros:}

MERCADO, Ruth. La construcción de la documentación etnográfica. In: ROCKWELL, Elsie; EZPELETA, Justa (Coords.). La práctica docente y su contexto institucional y social. México: Informe Final, 1987. v. 3, p. 140- 159.

\section{Artigos:}

MALDONADO, Ruth Mercado. Un debate actual sobre la formación inicial de docentes en México. Revista Psicologia Escolar e Educacional, v.14, n. 1, p. 149-157, jan./jun. 2010.

MERCADO, Ruth. Los saberes docentes en el trabajo cotidiano de los maestros. Infancia y Aprendizaje, México, n. 55, p. 59-72, 1991. p. $57-68,2005$.

La evaluación de profesores de educación básica en México: la carrera magisterial. Avance y Perspectiva, v. 24, n. 1 ,

RODRÍGUEZ, Pedro Antronio E.; MALDONADO, Ruth Mercado. Procesos de negociación de significado en una escuela normal mexicana. Psicologia e Sociedade, v. 20, n. 3, p. 391-401, 2008.

TAVERA, Epifanio; MALDONADO, Ruth Mercado. La mediación social en la apropiación de una nueva propuesta para la alfabetización inicial. Educação e Pesquisa, v. 35, n. 2, p. 331-350, maio/ago. 2009. 